\title{
Letters
}

\section{Motor evoked potentials of the respiratory muscles}

I read with interest the article by Lissens et al on the new technique for investigating respiratory muscles in tetraplegic patients. ${ }^{1}$

I was surprised to note the statement that:-

'The abdominal muscles (ie the abdominal oblique, the rectus and transversus abdominis muscles) and the transversus thoracis muscle (also called triangularis sterni or sternocostalis muscle) are active during quiet expiration in tetraplegic subjects.'

They quote from Mortola et al. $^{2}$

This is not in accordance with the studies that I carried out in tetraplegic patients with $\mathrm{EMG}^{3}$ nor did movement studies show any activity prior to inspiration., ${ }^{4,5}$ These studies showed no activity in the abdominal muscles during quiet ventilation.

I looked up the reference by Mortola and Stan'Ambrogio who gave no support to their statement.

With regard to the subjects that they employed. They studied four spinal injured patients with incomplete spinal cord lesions. If they had incomplete spinal cord lesions then some pathways could be present from the brain to the ventilatory muscles and would thus invalidate their findings. The normal method of research is to select subjects with complete cord transections.

1. Motor evoked potentials of the respiratory muscles in tetraplegic patients. Lissens MA. Vanderstraeten GG. Spinal Cord (1996) 34, 673-678.

2. Mortola JP and Sant'Ambrogio G. Motion of the rib cage and the abdomen in tetraplegic patients. Clinical Science and Molecular Medicine (1978) 54, 25-12.

3. Guttman L and Silver JR. Electromyographic studies on reflex activity of the Intercostal and abdominal muscles in cervical lesions. Paraplegia 1964/5 2 235-246.

4. Moulton A, Silver JR. Chest movements in patients with traumatic injuries of the cervical cord. Clin Sci 1970; 39: 407-422).

5. Morgan MDL, Gourlay AR, Silver JR, Williams SJ, Denison DM. Thorax 1985: 40: 613-617).

J Silver

Consultant in Spinal Injuries

Wendover

Buckinghamshire, UK

\section{Reply from Dr MA Lissens}

When stating that 'the abdominal muscles are active during quiet expiration in tetraplegic subjects' (quoted from the paper by Mortola et al., 1978) we obviously referred to incomplete spinal cord-injured, (in this case incomplete tetraplegic) patients. However, we aware that studies carried out in tetraplegic patients show no EMG-activity in their abdominal muscles during quiet ventilation, nor any movement of their chest prior to inspiration. Therefore, we should have stated in our paper that the abdominal muscles are active during expiration in incomplete tetraplegic subjects.

Our study on motor evoked potentials of the respiratory muscles in tetraplegic patients confirms this finding. Indeed, no motor evoked potentials could be obtained from the abdominal muscles in the complete tetraplegic patients, except in one $\mathrm{C} 3$ tetraplegic patient in whom we found a very small response during expiration, with a very delayed latency time. All patients examined in this study had clinically incomplete tetraplegia due to a high cervical cord lesion above C6 level, but their abdominal muscles were clinically completely paralysed. Clinically complete, however, does always imply neurophysiologically complete. Some spinal cord-injured patients can have clinically complete lesions, but brain input to some of their muscles may be partially preserved. This was mostly probably the case in one $\mathrm{C} 3$ tetraplegic patient in whom some motor evoked potentials were obtained from the abdominal muscles. When using the term incomplete in our paper, we referred to incompleteness of upper extremity muscle function. The fact that we did not make this distinction in the introduction of our paper, may indeed mislead or confuse some readers.

MA Lissens, MD

\section{Special precautions to be observed while using alprostadil in patients with spinal cord injury}

Intracavernosal injection of alprostadil is being widely used in patients with spinal cord injury to achieve adequate penile erection to perform satisfactory sex. Based on our clinical experience of treating spinal cord injury patients with intracavernosal administration of alprostadil, we wish to emphasise certain precautions that need to be observed in order to avoid the side-effect of priapism while using this modality of treatment in this group of patients.

1. As mentioned in the British National Formulary (Number 32, September 1996, page 350), the first dose of alprostadil when it is administered intracavernosally to achieve penile erection in patients with spinal cord injury should be only 1.25 micrograms. Some spinal cord injury patients are able to achieve adequate erection with a small dose as 2 micrograms of alprostadil. Thus, the dosage requirements of alprostadil in patients with spinal cord injury are less as compared to the dose for able-bodied individuals.

2. We recommend increasing the dose of alprostadil in steps of 2 micrograms to determine the optimum dose for a given patient with spinal cord injury (e.g. 1.25 micrograms, 2 micrograms, 4 micrograms, 6 micrograms, 8 micrograms, 10 micrograms, and so on), in contrast to the increments of 5 micrograms after reaching the third dose of 5 micrograms as practised routinely (e.g. 1.25 micrograms, 2.5 micrograms, 5 micrograms, 10 micrograms, 15 micrograms, 20 micrograms, and so on), Recently, the dose of alprostadil was increased inadvertently from 10 micrograms to 14 micrograms during the dose-finding phase, in a 40 year old traumatic tetraplegic patient in order to achieve better quality erection. This increase of 4 micrograms in the dosage of 
alprostadil resulted in prolonged erection requiring aspiration of the corpus cavernosum and the intracavernosal injection of 200 micrograms of phenylephrine to obtain penile detumescence. By increasing the dose of alprostadil in steps of only 2 micrograms, we have been able to avert the side-effect of prolonged erection. Of course, by using the 2 micrograms increments instead of 5 micrograms, the dose-finding phase is prolonged by one to two weeks. But it is worth while observing such a precaution in patients with spinal cord injury in order to avoid the mishap of priapism.

3. Another important fact worth mentioning is the dosage modification required in those spinal cord injury patients who develop reflex penile erection, which is per se inadequate for accomplishing the sexual act. Some spinal cord injury patients develop reflex penile erection as the penis is handled, e.g. while removing the penile sheath prior to intracavernosal injection of alprostadil. Although a given patient might have been established on a dosage of say, 8 micrograms of alprostadil, if he develops penile erection just prior to the administration of alprostadil, we recommend that he should wait until complete detumescence is achieved before proceeding with the intracavernosal injection of his regular dose of alprostadil, or if the circumstances do not permit any procrastination, he or his partner proceeds with the administration of a reduced dose of alprostadil, preferably the dose being halved. In the example cited above, we advocate intracavernosal administration of 4 micrograms of alprostadil instead of 8 micrograms. If the usual dose of alprostadil is administered in the presence of reflex penile erection, the spinal cord injury patient may run the risk of developing drug-induced priapism.

By observing these special precautions while administering alprostadil intracavernosally, the chances of developing the serious side-effect of drug-induced prolonged erection will be minimised in spinal cord injury patients who form a distinct group as opposed to the able-bodied individual with erectile dysfunction.

S Vaidyanathan

BM Soni

KR Krishnan

Regional Spinal Injuries Centre

Town Lane

Southport, Merseyside PR8 6PN, UK 